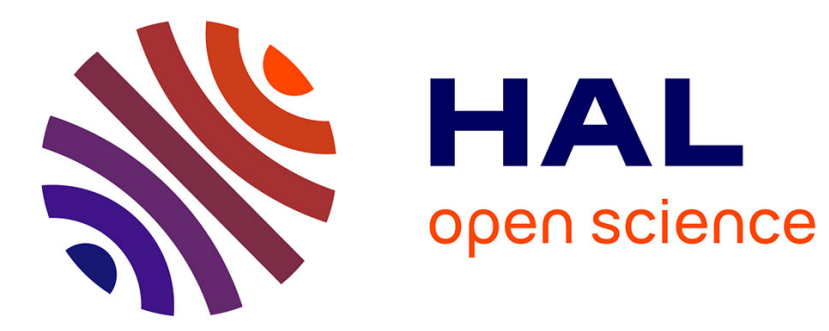

\title{
Five-phase version of 12slots/8poles three-phase Synchronous Machine for Marine-propulsion
}

Hussein Zahr, Eric Semail, Franck Scuiller

\section{To cite this version:}

Hussein Zahr, Eric Semail, Franck Scuiller. Five-phase version of 12slots/8poles three-phase Synchronous Machine for Marine-propulsion. IEEE Vehicle Power and Propulsion Conference, Oct 2014, Coimbra, Portugal. pp.6, 10.1109/VPPC.2014.7007073 . hal-01069907

\section{HAL Id: hal-01069907 https://hal.science/hal-01069907}

Submitted on 13 Oct 2017

HAL is a multi-disciplinary open access archive for the deposit and dissemination of scientific research documents, whether they are published or not. The documents may come from teaching and research institutions in France or abroad, or from public or private research centers.
L'archive ouverte pluridisciplinaire HAL, est destinée au dépôt et à la diffusion de documents scientifiques de niveau recherche, publiés ou non, émanant des établissements d'enseignement et de recherche français ou étrangers, des laboratoires publics ou privés. 


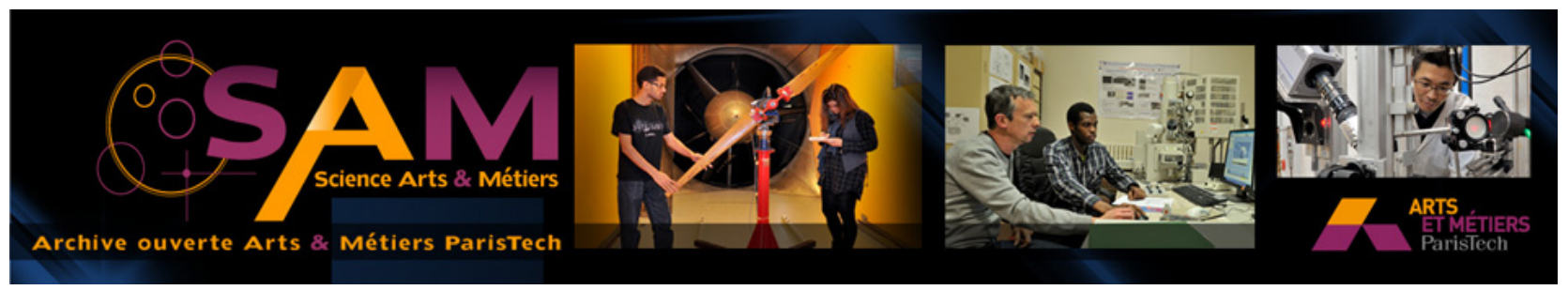

Science Arts \& Métiers (SAM)

is an open access repository that collects the work of Arts et Métiers ParisTech researchers and makes it freely available over the web where possible.

This is an author-deposited version published in: http://sam.ensam.eu Handle ID: .http://hdl.handle.net/10985/8654

\section{To cite this version :}

Hussein ZAHR, Franck SCUILLER, Eric SEMAIL - Five-phase version of 12slots/8poles threephase Synchronous Machine for Marine-propulsion - 2014 


\section{Five-phase version of 12slots/8poles three-phase Synchronous Machine for Marine-propulsion}

\author{
Hussein Zahr ${ }^{(1,2)}$, Eric Semail ${ }^{(1)}$ \\ (1) L2EP, Electrical Engineering and Power \\ Electronics Laboratory \\ Arts et Metiers Paris Tech \\ 8, Boulevard Louis XIV Lille, France \\ Hussein.ZAHR @ensam.eu \\ Eric.SEMAIL@ensam.eu
}

\author{
Franck Scuiller \\ (2) Naval Academy Research Institute \\ Brest, France \\ franck.scuiller@ecole-navale.fr
}

\begin{abstract}
Multiphase machines are widely used in electric marine propulsion especially because of their fault-tolerance which allows to guarantee the propulsion even if a fault occurs in the electrical system. Besides, the 12 slots/8 poles three-phase machine (12/8/3 machine) with fractional slot concentrated windings is known for its low level of Permanent Magnet eddy currents losses, making it adequate for compact high speeds applications. Since this interesting property is due to a 0.5 value for the number of slots per pole and per phase $(\mathrm{spp}=0.5)$, then the paper examines a five-phase 20 slots/8poles (20/8/5 machine) fault tolerant machine whose $\mathrm{spp}=\mathbf{0 . 5}$. Using an analytical model, the copper losses and an estimation of the magnet losses for the two machines are presented and a comparison is done between the two machines. The results show that the $20 / 8 / 5$ has more Joules losses than 12/8/3 but lower magnet eddy current losses. Since the Joules losses can be easily evacuated more than the magnet losses, the 20/8/5 machine can be considered as the fault tolerant version of the 12/8/3 machine. Finally, the overall losses for the two machines are computed, the losses in 20/8/5 machine are less than in 12/8/3 machine. A finite element calculation is carried out in order to validate the analytical predictions.
\end{abstract}

Keywords-Concentrated windings, electrical propulsion, copper losses, eddy-current losses, Permanent magnet machines.

\section{INTRODUCTION}

Nowadays, electrical machines are widely used in the automotive and marine propulsion. In these applications, the reliability of the propeller is required to ensure the functioning in fault mode. In addition, given the limited volume dedicated to the propeller, the propulsion must have a high compactness. Multiphase machines have the ability to satisfy these requirements, while providing other benefits: low torque ripple, the ability to produce a significant torque using high order harmonic injection to enhance torque density [1-6] and reducing the current per phase by splitting the same power over a greater number of phases reducing the constraints on power electronics [7]. Regarding the machine design, two important criteria must be adapted to obtain the desired performance for multiphase machine: winding distribution and the geometry of permanent magnet layer. However, winding distribution is determined by the winding configuration and slot/pole combination. Due to its advantages and its simple structure which is easy to manufacture and recycle, concentrated winding are chosen as winding configuration [8][9].With reference to distributed winding [2][3][4][6], this configuration can enhance the third harmonic term in the MMF spectrum. Thus, this harmonic, if exploited, can increase significantly the torque density of the machine[5].The main drawback of such configuration is the magnetomotive force (MMF) spectrum which contains harmonics moving asynchronously with the rotor, inducing eddy-current losses in the different rotor parts, in particular permanent magnets [8][10][11]. The comparison introduced in [11] indicates that the rotor losses depend on slots/poles combination. These rotor losses, which are difficult to evacuate, heat the magnets whose magnetic properties are highly depending with the temperature. Thus, demagnetization phenomena can occur degrading the machine performances. As consequence, the choice of the slot/plot combination is important to determine the MMF harmonic content which impacts the amount of the rotor losses at high speed [12][13].The comparison between the different combinations slots/poles/phases in order to avoid bad choice of this combination is introduced in[12][14][15][16]. A general analytical model of magnet eddy-current losses is developed and the average value of magnet losses for each combination slots/poles/phase is computed [16]. The results indicate that the combination 0.5 slot/pole/phase does not produce any sub harmonic in the MMF spatial spectrum, so this combination appears as the combination with the lower level of magnet losses. It is a reason why such $12 / 8 / 3$ machine are used in hybrid automotive applications developed by Toyota and Honda car-makers.

Besides, in low voltage (48V) applications with significant power $(>10 \mathrm{~kW})$, the phase currents in a three-phase machine become too high for standard power components and connections. If a low voltage level is preferable (pleasure boat or automotive) because it is a security level of voltage, then the only solution to decrease the phase current is to increase the phase number. Furthermore multi-phase machines are all the more relevant as it improves the torque density and reduces the torque ripples. Finally, when a fault-tolerance capability is also appreciated or required, such as in electrical marine applications, then multiphase machines become necessary. 
A five-phase machine with $\mathrm{spp}=0.5$ can be a solution for operating at low voltages and high frequencies with a low level of eddy-current losses in Permanent Magnets.

In this paper, a 20slots/8poles five-phase machine with $\mathrm{spp}=0.5$ is chosen despite its low (0.588) first harmonic winding factor. The reason is that, regarding the control side, star-connected multiphase machines present particular properties which give more design and control possibilities than the three-phase machines. Thus, it is common to consider a five-phase machine as a set of two-phase virtual machines electrically independent but magnetically coupled (multimachine decomposition) [17][18] . The two (d,q) type machines, characterized by different harmonic families (associated respectively with first and third harmonics), can be controlled independently. As consequence, when considering a five-phase machine, the third harmonic current injection can boost the torque which increases the machine torque density [2]. It should be mentioned that the third harmonic current injection can be used to increase the torque of multiphase induction machine. For example, according to [5], with reference to a standard three-phase induction machine, it is shown that this strategy applied to a six-phase induction machine equipped with concentrated winding can increase the torque by $40 \%$. In [3], when using this control strategy, the gain is about $10 \%$ with a five-phase induction motors referring to a standard three-phase one (with sinus supply). In [6] that focuses on five-phase PM machines, a torque increase by $17 \%$ is shown with reference to a three-phase PM machine. These torque enhancements are all obtained for multi-phase machines equipped with concentrated windings in order to have a significant third harmonic term in the magnetomotive force. Finally, for a PM five-phase machine, the torque enhancement will be all the higher as the back-emf has a significant third harmonic term. This particularity for the third harmonic winding factor allows, with an adapted PM rotor design, to use the third harmonic of current to increase the torque, particularly at low speed. This is the original advantage of this machine over the $12 / 8 / 3$ machine which can be supplied only with the first harmonic current.

This paper deals with the comparison between this two kinds of machines, the last being intended to drive ship propeller, typically for pleasure boat with $48 \mathrm{~V}$ battery packs with a fault tolerance property.

In section II, the system is described with a focus on the two rotor magnet configurations for the two kinds of machine.

In section III, copper losses are calculated and compared for a given torque and different strategies of supply.

In section IV, at first the magnet losses are evaluated and compared in the same conditions as in section III.

In section $\mathrm{V}$, a global comparison is achieved concerning the losses showing equivalent global losses.

\section{Design SPECIFICATION OF ShIP Propeller AND MACHINE CONFIGURATIONS}

The chain of naval propulsion is shown in figure (1):
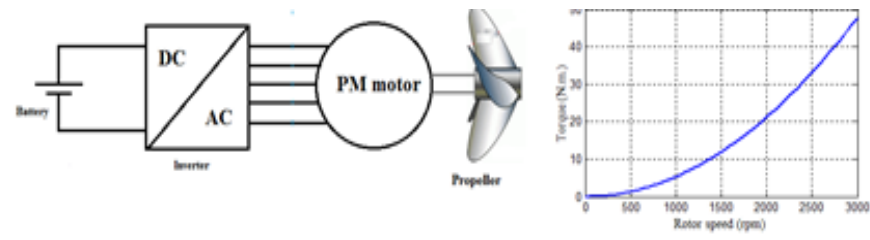

Fig. 1. Chain of electrical naval propulsion.

In steady state operation, the propeller follows a profile such that the load torque is proportional to the square of the speed[19]:

$$
T_{\text {shaft }}=K \Omega^{2}
$$

Where $T_{\text {shaft }}$ is the propeller torque and its rotation speed. This propeller has a base speed of $3000 \mathrm{rpm}$ and the power at this speed is $9 \mathrm{~kW}$. As mentioned in the introduction, we have two posibilities for the electromagnetical design: the $12 / 8 / 3$ or the $20 / 8 / 5$. The two machines have the same geometrical parameters. The basic parameters of the propulsion machine are given in table (I):

TABLE I. BASIC PARAMETERS OF THE PROPELLER

\begin{tabular}{|c|c|}
\hline Machine & $12 / 8 / 3$ \\
\hline Point de base & $9 \mathrm{~kW} @ 3000 \mathrm{tr} / \mathrm{min}$ \\
\hline Effective length & $280 \mathrm{~mm}$ \\
\hline Outer diameter & $140 \mathrm{~mm}$ \\
\hline Stator yoke thickness & $7.8 \mathrm{~mm}$ \\
\hline Slot depth & $6.4 \mathrm{~mm}$ \\
\hline Air-gap length & $1 \mathrm{~mm}$ \\
\hline Magnet layer thickness & $3 \mathrm{~mm}$ \\
\hline Rotor thickness yoke & $7.8 \mathrm{~mm}$ \\
\hline $\begin{array}{l}\text { Slot width to slot pitch } \\
\text { ratio }\end{array}$ & 0.5 \\
\hline $\begin{array}{c}\text { Slot opening to slot } \\
\text { pitch ratio }\end{array}$ & 0.5 \\
\hline Filling factor & 0.8 \\
\hline
\end{tabular}

As mentioned previously, fractional slot concentrated winding permanent magnet synchronous machines are good solutions for this application. Bearing in mind that the machine performance depends on the stator and rotor configuration, we try to adapt the magnet layer to the winding in order to improve the performance. Concerning the winding, the configurations with $S_{p p}=0.5$ are favored. It should be noted that the winding distribution is chosen to maximize the winding factor of the first harmonic for $12 / 8 / 3$ and for the first and the third harmonic for $20 / 8 / 5$, where this choice allows to enhance the torque density, by injecting the third harmonic. Furthermore, this configuration allows the 20/8/5 machine to operate at low speed ( $3 p$ pairs of pole) or at high speed ( $p$ pairs of pole) with an electronic pole changing effect. The second topic in this part is the choice of magnet layer geometry for the two machines under consideration (the 12/8/3 and the 20/8/5). The 12/8/3 machine has a zero winding factor for the third harmonic. Therefore, we decide to design the magnet layer to eliminate 
the air gap flux density third harmonic, thus reducing the cogging torque. The pole arc to pole pitch ratio is then chosen to be $2 / 3$. For the $20 / 8 / 5$ machine, the same magnet volume as for the $12 / 8 / 3$ machine must be used. Taking into account the winding factors of the first and the third harmonic, the magnet layer shape is arranged in order to have the same torque to current contribution when using the first harmonic current component or when using the third harmonic one. This objective implies the first harmonic (E1) and the third harmonic (E3) terms of the back-emf must be equal. In order to increase the third harmonic term of the air gap flux density, an interpolar gap $x$ is introduced in each pole as in the figure (2):

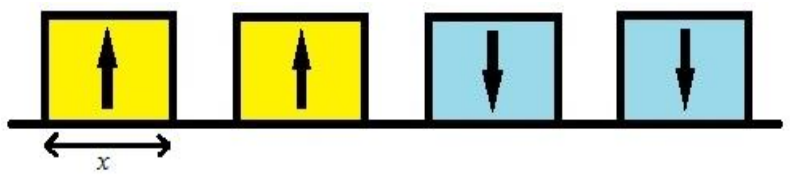

Fig. 2. Magnet layer of 20/8/5 machine .

Let $\mathrm{K}$ the ratio of magnet width $\mathrm{x}$ over the polar pitch. The better choice is $K=1 / 3$ to obtain two virtual machines with the same torque production ability. In order to prove the validity of this solution the back-emf of 20/8/5 machine is calculated analytically. The results are validated with finite elements calculations. Figure (3) shows the comparison between the two methods: quite close estimations are obtained.

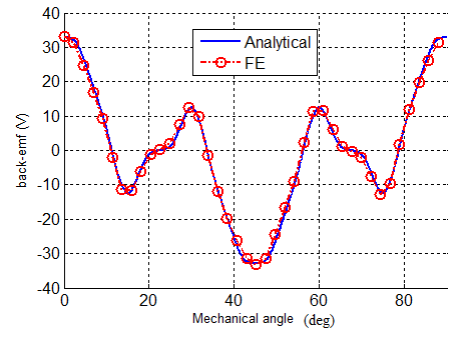

(a)

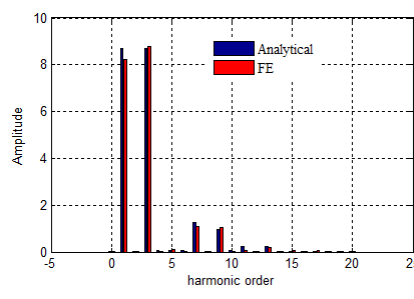

(b)

Fig. 3. (a) Back-emf for $20 / 8 / 5$ machine . (b) Harmonic content of back-emf

The winding distributions over a pole pair for the two machines are drawn in figure(4):

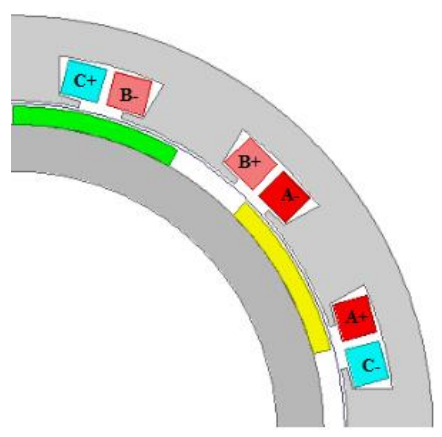

(a)

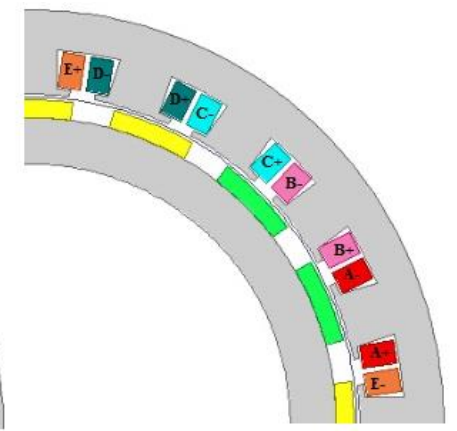

(b)

Fig. 4. (a) 12/8/3 machine . (b) 20/8/5 machine.

\section{COPPER LOSSES}

In many cases, Copper losses are the most dominant losses in electrical machines at low electrical frequency. They are divided into DC losses and AC losses due to skin effect. This paper deals only with DC losses: the skin effect is neglected. In addition, the end windings effect is disregarded. Consequently, copper losses are given by (2):

$$
P_{j}=m R I^{2}
$$

Where $m$ is the number of phases, $R$ is the resistance of coils and $I$ is the RMS current. In this section, a comparison between the copper losses of $12 / 8 / 3$ and $20 / 8 / 5$ is carried out. The $12 / 8 / 3$ machine is supplied with sinusoidal current. For the 20/8/5 machine, in order to obtain the base torque with the base current, we can control the machine currents in three ways: with only fundamental, with only third harmonic or with both fundamental and third harmonic. The following analysis is made with Maximum Torque per Ampere (MTPA) control assumption applied to the three strategies. The expression of the maximum torque is given by:

$$
T_{e m}=m \frac{\sum_{h} E_{h} I_{h}}{2 \Omega}
$$

Where $\mathrm{h} \in 2 \mathrm{~N}+1$ and $\mathrm{h}<\mathrm{m}((\mathrm{h}=1$ if $\mathrm{m}=3, \mathrm{~h}=1$ or $\mathrm{h}=3$ if $\mathrm{m}=5)$. Thus, for $12 / 8 / 3$ machine, the torque is produced by the first harmonic only, while the $20 / 8 / 5$ can be supplied by the first harmonic, the third or both. The required currents corresponding to the base torque for the two machines are given in table (II), the calculation is done analytically and the results are validated numerically.

TABLE II. RMS CURRENTS INJECTED AT BASE SPEED AND TORQUE

\begin{tabular}{|l|c|c|c|c|c|c|}
\hline \multirow{2}{*}{ Unit A } & \multicolumn{5}{|c|}{ Machines } \\
\cline { 2 - 6 } & \multicolumn{5}{|c|}{$\mathbf{2 0 / 8 / 5}$} & $\mathbf{1 2 / 8 / 3}$ \\
\hline \multirow{2}{*}{ Supply } & $\begin{array}{c}\text { First } \\
\text { harmon } \\
\text { ic }\end{array}$ & $\begin{array}{c}\text { Third } \\
\text { harmonic }\end{array}$ & \multicolumn{2}{|c|}{$\begin{array}{c}\text { Both first and third } \\
\text { harmonic }\end{array}$} & $\begin{array}{c}\text { First } \\
\text { harmonic }\end{array}$ \\
\cline { 5 - 6 } Ana & 207 & 208 & 104 & 103.5 & 146,7 & 193 \\
\hline Num & 219 & 205 & 102.2 & 109.3 & 149,6 & 206.5 \\
\hline
\end{tabular}

This difference between the currents values in the two cases can be explained by the difference between the analytical and FE estimations of the back-emf. The copper losses are the calculated in each case, according to the torque versus speed profile given by (1) and illustrated in figure (1). The results are shown in figure (5). 


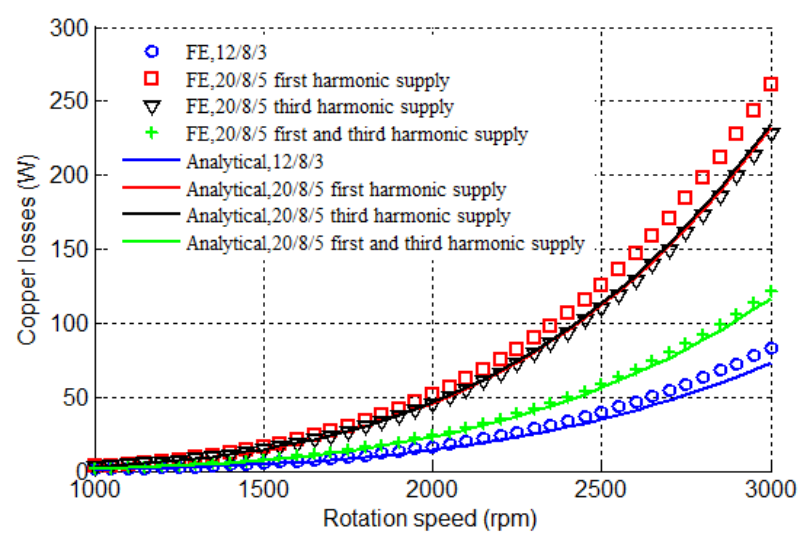

Fig. 5. Copper losses in the two machines 20/8/5 and 12/8/3.

According to figure(5), the 12/8/3 has the lower copper losses because of its higher fundamental winding factor. The supply of 20/8/5 machine with both the first and the third harmonic current harmonics reduce by half the copper losses. This is due to high winding factor of third harmonic (0.951) which compensates the additionnal losses. Therefore, the supply of 20/8/5 with these two harmonics is the better startegy. We can note that the slight difference between numerical and analytical calculations is due mainly to the difference between the analytical and numerical estimations of the back-emf, thus resulting to slight different analytical and numerical estimations of the required currents to obtain the wanted mean torque (as already observed in table (II)).

\section{MAGNET LOSSES}

Different phenomena can induce eddy-current losses in the rotor: asynchronous MMF harmonics, permeance variation and PWM harmonics [12]. In this paper we consider the eddy -current losses due to the MMF harmonics associated with the windings and those due to permeance variation. The MMF losses, called armature reaction PM losses depend on three factors [10][12]:

- The amplitude of the magnetic flux density in the airgap for the $v$-th MMF harmonic denoted $\mathrm{B}_{\mathrm{v}}$

- The relative speed of the MMF harmonics with respect to the rotor

- The ratio $\lambda_{\mathrm{v}} / \mathrm{w}$ : where $\mathrm{w}$ is the pole magnet width and $\lambda_{\mathrm{v}}=2 \pi \mathrm{R}_{\mathrm{r}} / \nu, \mathrm{R}_{\mathrm{r}}$ being the rotor radius.

The second type of the losses, called open circuit PM losses, is the permeance variation losses, which is induced by the variation of permanent magnet field due to slot effect. This type of losses depends generally on the slot-opening width. In this section we will examine these two types of losses. An analytical estimation for each type is carried out; the results are validated with FE estimation.

\section{A. Open circuit PM losses}

The estimation of open circuit permanent magnet losses is mentionned in [20] where an analytical method is developed to estimate these losses. The origin of these losses is the variation of PM magnetic flux density due to stator slot effect. Consequently, this losses depend generally on slot openning. Applying this method to the two machines 20/8/5 and $12 / 8 / 3$.we obtain the results illustrated in figure (6).

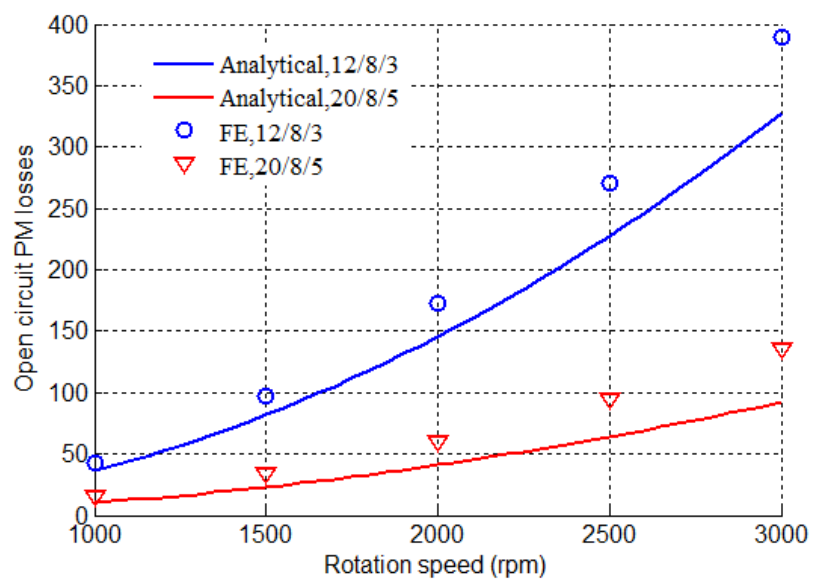

Fig. 6. Open circuit PM losses.

Figure (6) shows that analytical and numerical estimations are quite close. According to the two methods, the $12 / 8 / 3$ has more open circuit PM losses than of $20 / 8 / 5$. This is due to the bigger slot openning in $12 / 8 / 3$ machine, since the $20 / 8 / 5$ machine has more slots for the same stator diameter. In the next section, we will investigate the magnet losses due to armature reaction in order to calculate the total losses in magnet losses.

\section{B. Armature reaction PM losses}

The armature reaction PM losses is mainly due to the MMF space harmonics. These components move asynchronously with the rotor, inducing eddy currents in the magnet. The MMF harmonic content depends on the machine supply. We remind that the 20/8/5 can be supplied by either the first or the third current harmonic or both, whereas $12 / 8 / 3$ can be supplied with only the first harmonic. Each strategy of supply generates a particular MMF spectrum. Table (III) presents the MMF harmonics for each supply strategy for the two machines (where $c$ is an integer).

TABLE III. MMF SPECTRUM ACCORDING To THE SUPPly STRATEGY

\begin{tabular}{|l|c|c|}
\hline \multirow{2}{*}{ Supply } & \multicolumn{2}{|c|}{ Machines } \\
\cline { 2 - 3 } First Harmnic & $\mathrm{p}(5 \mathrm{c} \pm 1)$ & $\mathrm{p}(3 \mathrm{c} \pm 1)$ \\
\hline Third harmonic & $\mathrm{p}(5 \mathrm{c} \pm 3)$ & ------ \\
\hline $\begin{array}{l}\text { First and third } \\
\text { harmonic }\end{array}$ & $\mathrm{p}(5 \mathrm{c} \pm 1)$ and $\mathrm{p}(5 \mathrm{c} \pm 3)$ & \\
\hline
\end{tabular}


Figure (7) represents the MMF spectrum for each machine. The sign of each component represents the rotation direction. The positive sign indicates that the harmonic rotates in the same direction as the rotor; negative sign indicates that the two rotate in opposite direction. (a)

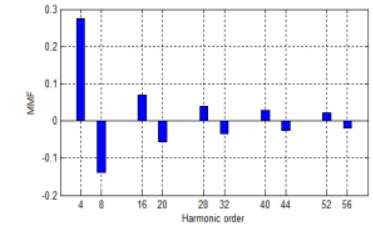

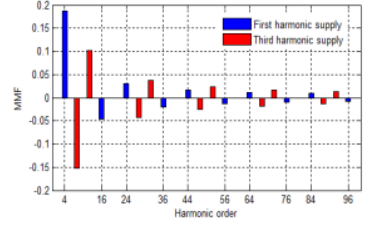

(b)
Fig. 7. MMF spectrum .(a) 12/8/3 machine; (b) 20/8/5 machine.

The model develloped in [21] is used to estimate analytically the armature reaction PM losses. Figure (8) shows the analytical estimation and FE calculation of this losses. The 20/8/5 machine supplied by the first current harmonic has the lower armature reaction PM losses. Thus, this strategy of supply is used at high speed. When the $20 / 8 / 5$ is supplied by only the third current harmonic, the losses are significant at high speed, which can lead to demagnetization. Thus, this strategy of control must be used only at low speed. The 20/8/5 has moderate losses when it is supplied by both the first and the third harmonic current, but this losses are still higher than those in 12/8/3 machine. Consequently, if the 20/8/5 machine is used in this application, it should be supplied by the first current harmonic at high speed, third current harmonic at low speed, both at intermediate speed. This conclusion is based on the armature reaction PM losses analysis. However, in order to determine the adequat strategy of supply, the total losses in PM should be calculated.

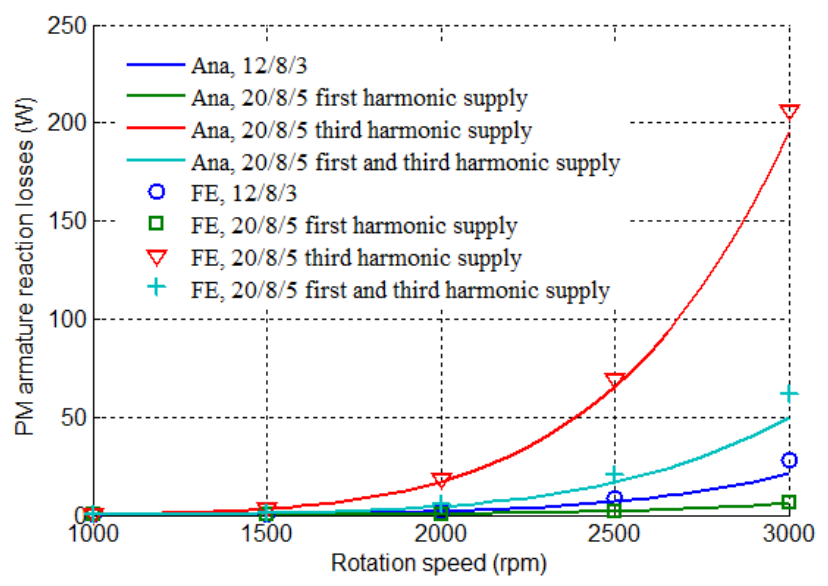

Fig. 8. Armature reaction PM losses.

Figure (9) shows the repartition of current density for the two machines. The following currents are due to armature reaction.

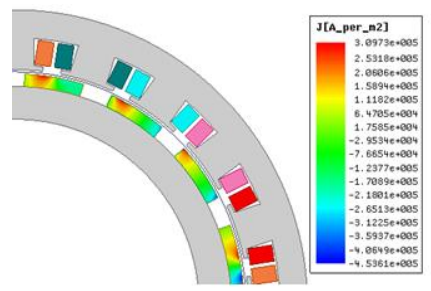

(a)

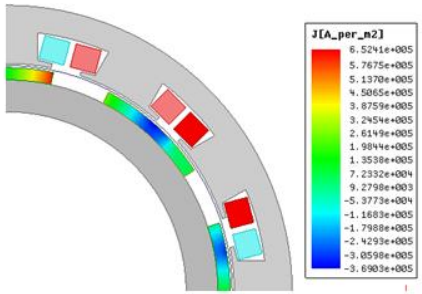

(b)
Fig. 9. Current density in PM. (a) 20/8/5 machine (first harmonic supply).(b) $12 / 8 / 3$ machine.

\section{Load PM losses}

In this section, the Total losses in PM are calculated when the two machines drive the mechanical load described by relation (1) and illustrated in figure (1). In these conditions, the total losses in PM are the combination of open circuit losses and armature reaction losses. Analytically, we estimate the PM losses by the sum of the open circuit losses and armature reaction losses. Numerically, the results are slightly different from the analytical sum as it can be observed in figure (10).

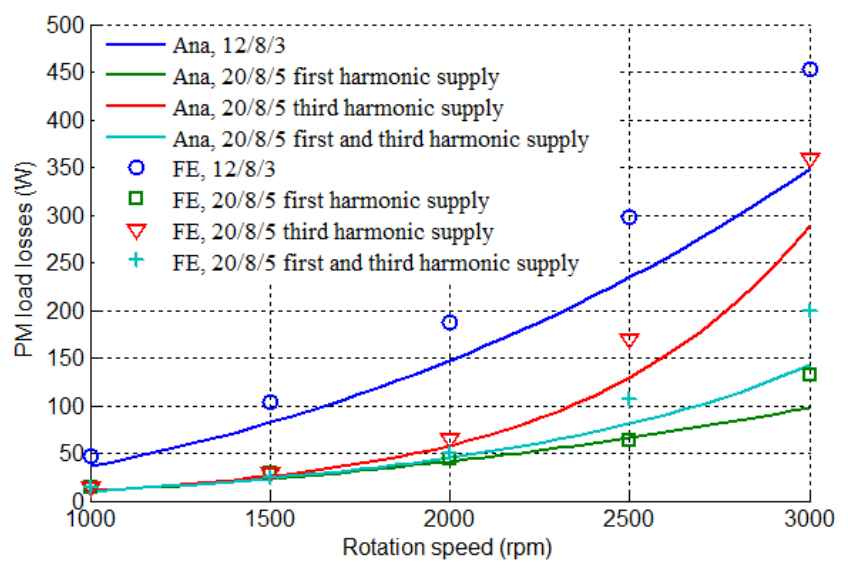

Fig. 10. PM losses on load in the two machines

The analytical and numerical estimations both indicate that the 20/8/5 machine has lower PM losses. This result is particularly appreciated because the evacuation of magnet losses to prevent from demagnetization is difficult to perform. More generally, in marine propulsion, the fault tolerant is appreciated, thus justifying the choice of the $20 / 8 / 5$ machine to replace the $12 / 8 / 3$ machine to drive the propeller. The supply strategy of $20 / 8 / 5$ machine mentionned in (B) is confirmed. It is clear that the open circuit PM losses in $12 / 8 / 3$ machine are large, which lead to significant PM losses in this machine.

\section{TOTAL LOSSES}

Neglecting the iron losses, the overall losses in the two machines are the sum of copper losses and magnet losses. The results are shown in figure (11). 


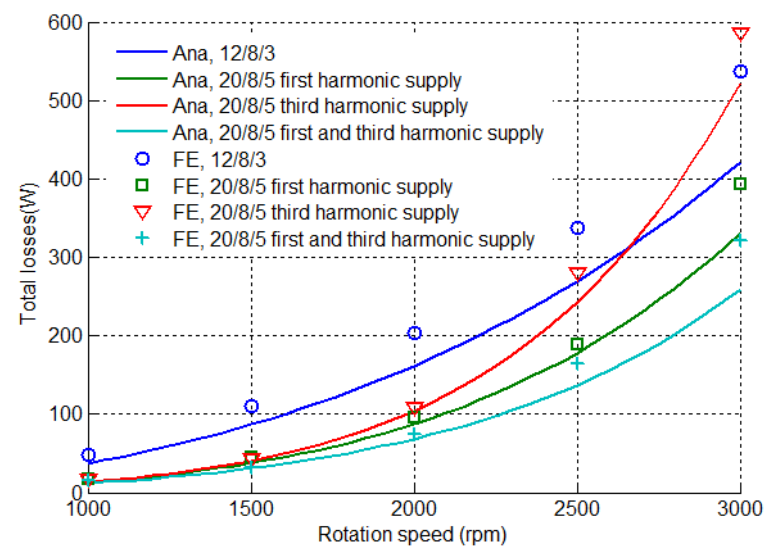

Fig. 11. Total losses in the two machines.

As we can see in figure (11), the $12 / 8 / 3$ machine has more losses than the 20/8/5 machine over the whole speed range if this machine is supplied by the first harmonic or both the first and the thrid harmonic. Consequently, we have two benefits for replacing the $12 / 8 / 3$ by $20 / 8 / 5$ one:

- A reliable propeller is obtained since the five phase machine has a fault tolerant capability.

- Lower losses can be obtained if an appropriate supply is chosen. The first harmonic and the first and the third harmonic supply are the adequate supplies for 20/8/5 machine.

Despite the higher copper losses, we can see that 20/8/5 has lower magnet losses. This point is interesting because, these losses, unlike the copper losses, are difficult to be evacuated by cooling. Hence, the 20/8/5 machine can be considered as the reliable multiphase version of $12 / 8 / 3$ machine.

\section{CONCLUSION}

In this paper, a comparison between two machines 20/8/5 and $12 / 8 / 3$ with the same number 0.5 of slots per pole and per phase is presented. The comparison takes into account the different possible supply strategies which are available for the 20/8/5 machine for a given torque. It appears that, with the chosen configuration of rotor magnet, the injection of both first and third current harmonic is the best solution for the 20/8/5 studied machine. In this case, the total losses are lower than in 12/8/3 machine. Moreover, it appears that the magnet rotor losses which are more difficult to evacuate than stator losses are lower for the 20/8/5. So the 20/8/5 machine, even if it presents a low first harmonic winding factor, can be used favorably in fault-tolerant low voltage application as it is the case for marine propulsion application as pleasure boat. This machine should be supplied by the first current harmonic at high speed, and by the third current harmonic at low speed, in order to avoid important losses PM over the whole speed range.

\section{REFERENCES}

[1] F. Scuiller, E.Semail and J.F. Charpentier, " Multi-criteria-based design approach of multi-phase permanent magnet low-speed synchronous machines," IET Electr. Power appl., 2009, vol.3, Iss.2, pp.102-110.
[2] H. A. Toliyat, T. A. Lipo, and J. C. White, "Analysis of a concentrated winding induction machine for adjustable speed drive applicationspart II (motor design and performance)," IEEE Trans Energy Conv.,Vol. 6,Dec. 1991, pp. 685-692.

[3] H. Xu, H. A. Toliyat, and L. J. Petersen, "Rotor field oriented control offive-phase induction motor with the combined fundamental and third harmonic currents," Proc. APEC'01 Conf., Vol. 1, 2001, pp. 392-398.

[4] Libo Zheng, J.E. Fletcher, B.W. Williams, Xiangning He, "DualPlane Vector Control of a Five-Phase Induction Machine for an Improved Flux Pattern," IEEE Transactions on Ind. Electr., vol.55, no.5, pp.1996,2005, May 2008.

[5] R. Lyra and T. A. Lipo, "Torque density improvement in a six-phase induction motor with third harmonic current injection," IEEE Ind. Appl.,Vol. 38, Sept.-Oct. 2002, pp. 1351-1360.

[6] L. Parsa and H. A. Toliyat, "Five-phase permanent-magnet motor drives," IEEE Trans. Ind. Appl., vol. 41, no. 1, pp. 30-37, Jan./Feb. 2005.

[7] E. Levi, "Multipahse electric machines for variable-speed applications, IEEE Trans.on Industrial electronics, vol.55, no.5, pp.1893-1909, 2008.

[8] A.M.EL-Refaie, "Fractionnal-slot concentrated-windings synchronous permanent magnet machines:opportunities and challenges," IEEE Trans. on Industrial Electronics, vol. 57, no. 11, January 2010.

[9] L.Alberti and N.Bianchi, "Theory and design of fractionnal-slot multilayer windings," IEEE Trans. on Industry applications, vol. 49, no. 12, March/April 2013.

[10] N.Bianchi and E.Fornasiero, "Impact of MMF space harmonic on rotor losses in fractionnal-slot permanent-magnet machines," IEEE Trans. On energy conversion, vol. 24, no. 2, June 2009.

[11] N. Bianchi and E. Fornasiero, "An index of rotor losses in three-phase fractional-slot permanent magnet machines," IET Elect. Power Appl., vol. 3, no. 5, pp. 381-388, Sep. 2009.

[12] B.Aslan, E.Semail, J. Legranger, "Slot/pole Combinations Choice for Concentrated Multiphase Machines dedicated to Mild-Hybrid Applications", IECON '11, Australia, Nov. 7-10 2011

[13] E. Fornasiero, L. Alberti, N. Bianchi, S. Bolognani, "Considerations on Selecting Fractional-Slot Nonoverlapped Coil Windings," IEEE Trans. on Industry Applications, vol.49, no.3, pp.1316,1324, MayJune 2013.

[14] E.Fornasiero, N.Bianchi and S.Bolognani, "Rotor losses in fractionnal slot three-phase and five-phase PM machines," ICEM 2010, Roma.

[15] E. Fornasiero, N. Bianchi, S. Bolognani, "Slot Harmonic Impact on Rotor Losses in Fractional-Slot Permanent-Magnet Machines", IEEE Trans.on Industrial Electronics, pp 2557 - 2564 Vol. 59, n 6, June 2012.

[16] B. Aslan, E. Semail, J. Legranger, "General Analytical Model of Magnet Average Eddy-Current Volume Losses for Comparison of Multi-phase PM Machines with Concentrated Winding," IEEE Trans. on Energy Conversion, march 2014, Vol29, n¹, pp. 72-83.

[17] F. Scuiller,"Développement d'outils de conception de machines polyphasées à aimants utilisant l'approche multi machine," Ph.D. dissertation, ENSAM, France, Décembre 2006.

[18] X. Kestelyn, E. Semail, "Vectorial Modeling and Control of Multiphase Machines with Non-salient Poles Supplied by an Inverter", Chap7 in book " Control of Non-conventional Synchronous Motors", ISTE Ltd and John Wiley \& Sons Inc, 2012.

[19] G.Filliau, A. Bondu and L. Mazodier," The all-electric shipcomponents state-of-the-art," Techniques de l'ingénieur, D5615, Febuary 2001.

[20] Z.X.Fang, Z.Q.Zhu, L.J.Wu, Z.P.Xia, "Simple and accurate analytical estimation of slotting effect on magnet loss in fractionnal slot surface mounted PM machines", IEEE 2012 XXth International Conference on Electrical Machines (ICEM) - Marseille, France.

[21] D. Ishak, Z. Q. Zhu, and D. Howe, "Eddy-Current Loss in the Rotor Magnets of Permanent-Magnet Brushless Machines Having a Fractional Number of Slots Per Pole", IEEE Transactions on magnetics, vol. 41, no. 9, september 2005. 